\title{
AC 2009-2344: ADVANCED VEHICLE DYNAMICS: THEORY IN PRACTICE
}

\section{Sangram Redkar, Arizona State University}

Dr. Redkar completed his PhD from Auburn University in 2005. He worked at Archangel System Inc., Auburn from 2005 to 2007. He joined the Department of Engineering Technology, Arizona State University as an assistant professor in Fall-07. His professional activities include: Member: ASME, ASEE, Reviewer for following international journals: Nonlinear Dynamics, Journal of Vibration and Acoustics, Communications in Nonlinear Science, ASME Journal of Computation and Nonlinear Dynamics. His areas of research are Nonlinear Dynamics, Inertial Navigation and Engineering Education. 


\title{
Advanced Vehicle Dynamics: Theory in Practice
}

\begin{abstract}
A novel course in vehicle dynamics was offered in fall-08 by Engineering Technology Department at Arizona State University (ASU). This course titled 'Advanced Vehicle Dynamics' was based on multi-body dynamics approach to vehicle dynamics with focus on computational analytical dynamics. It was offered as a graduate course with a unique class composition like $40 \%$ students with 10 or more years of industrial experience, $20 \%$ students with 20 or more years of industrial experience, $30 \%$ graduate students with less than 2 years of experience and $10 \%$ senior undergraduate students, interested in pursuing career in automotive engineering. This paper describes the course structure, objectives; challenges faced by the instructor because of diverse class composition and different student expectations, project based learning approach adopted in the course, student participation and the course outcomes. It is interesting to note that some of the project assigned in this course were 'real life problems' faced by a leading aftermarket automotive manufacturer. The class, as a team, brainstormed on appropriate strategies to address the project problems. The computational tools and instructional material for the lab were donated by MSC software that actively participated in enhancing the educational experience. This course presents one of the many efforts pursued by the Engineering Technology Department to bring industry and academia closer by giving an opportunity to practicing engineers to 'sharpen the skills' and regular students a 'feel of the real world engineering'.
\end{abstract}

\section{Introduction:}

At Arizona State University, the Department of Engineering Technology (formerly Mechanical and Manufacturing Engineering Technology Department) has implemented an automotive concentration within its Mechanical Engineering Technology program. Some of the undergraduate courses offered by the department in this concentration are MET 321 - Introduction to Automotive Engineering, MET 421 - Vehicle Powertrains, MET 423 - Vehicle Chassis Design, MET 424 - Vehicle Electrical Systems, MET 426 Vehicle Thermal Design, MET 427 - Vehicle System Integration and Testing. Despite of ASU's geographical remoteness from the Michigan and upper Midwest heart of the USbased automotive industry, the automotive concentration has experienced explosive enrollment growth (of both in-state and non-resident students). In fall-08, the graduate students and practicing engineers requested the author to offer a course in computational vehicle dynamics that will enable them to understand vehicle dynamics from multi-body analytical dynamics point of view. This course also aimed at introducing students to a very powerful computational vehicle dynamics software suite-MSC-ADAMS by MSCSoftware ${ }^{1}$.

Development of such a course needed strong collaboration from Industry, MSC software and the University. The central idea behind the course was that the analytical vehicle dynamics theory would be covered by the author (instructor), U-Haul Technical Center ${ }^{2}$ 
would suggest and support suitable 'real life' projects and students will work on these projects using MSC software suite (specifically, ADAMS View, ADAMS Car, ADAMS Chassis etc). MSC University program ${ }^{3}$ supported this idea and provided ASU, an academic network license for 150 seats at a much discounted price as grant. This academic license allowed students to work on the class projects and homework problems using MSC-ADAMS. MSC University program manager also provided the instructor MSC-ADAMS study material that is used by MSC software in their commercial training programs.

The Multibody Systems Approach to Vehicle Dynamics by M. Blundell and D. Harty ${ }^{4}$ was selected as a text for the course as it discussed computational multi-body dynamics with software applications. Prof. Blundell from Coventry University ${ }^{5}$, UK kindly provided his teaching material and assignments to the instructor. Thus, the instructor could offer this course in fall-08 due to generous support from MSC Software, U-Haul Technical Center and Coventry University in UK. Thus, this was a very unique endeavor where a team from industry, universities from US and abroad came together so that the student can have a very good 'cutting edge and hands on' learning experience.

\section{Course Learning Objectives and syllabus structure:}

This course had 2 primary course learning objectives. After successful completion of the course

1. The students should be able to understand multi-body system approach to vehicle dynamics.

2. The student should be able to use multi-body computational software (MSC-ADAMS) to solve vehicle dynamics problems.

It is to be noted that vehicle dynamics is a complex subject that involves concept from design, system analysis, vehicle handling and safety. In order to understand multi-body system approach to vehicle one has to consider various subsystems such as steering, suspension, tires, chassis and so on. The second objective focuses on understanding and modeling the subsystems and assemblies in MSC-ADAMS, parameter specifications, studying performance, simulations and interpretation of test results. Thus, the lecture schedule comprised of topics (shown in table 1) from vehicle dynamics introduction to simulation and testing incorporating MSC training material as appropriate.

\begin{tabular}{|c|c|c|c|}
\hline $\begin{array}{l}\text { Topic } \\
\text { No }\end{array}$ & Topic Name & Weeks & Focus Area \\
\hline 1 & Introduction & 1 & $\begin{array}{lrr}\text { Course } & \text { Outline, } & \text { Projects } \\
\text { discussion } & \text { and } & \text { project } \\
\text { assignments. } & & \\
\end{array}$ \\
\hline 2 & $\begin{array}{l}\text { Kinematics and Dynamics of } \\
\text { Rigid Bodies }\end{array}$ & 2,3 & $\begin{array}{l}\text { Review of concepts in Dynamics } \\
\text { of Multi-body systems }\end{array}$ \\
\hline 3 & $\begin{array}{l}\text { Multi-body Systems Simulation } \\
\text { Software }\end{array}$ & 4,5 & $\begin{array}{l}\text { Introduction to ADAMS-View, } \\
\text { ADAMS-Car }\end{array}$ \\
\hline 4 & $\begin{array}{l}\text { Modeling and Analysis of } \\
\text { Suspension Systems }\end{array}$ & 6,7 & $\begin{array}{l}\text { Types of suspensions, suspension } \\
\text { modeling and analysis using }\end{array}$ \\
\hline
\end{tabular}




\begin{tabular}{|l|l|l|l|}
\hline 5 & $\begin{array}{l}\text { Tire Characteristics and } \\
\text { Modeling }\end{array}$ & 8,9 & $\begin{array}{l}\text { ADtroduction to tire models, } \\
\text { applications of tire models, } \\
\text { modeling tire in ADAMS-car }\end{array}$ \\
\hline 6 & $\begin{array}{l}\text { Modeling and the Assembly of } \\
\text { the Full Vehicle }\end{array}$ & $\begin{array}{l}10,11, \\
12\end{array}$ & $\begin{array}{l}\text { Modeling and assembling } \\
\text { subsystems to create full vehicle }\end{array}$ \\
\hline 7 & $\begin{array}{l}\text { Simulation Output and } \\
\text { Interpretation }\end{array}$ & 13,14 & Virtual testing using ADAMS-Car \\
\hline 8 & Project presentations & 15,16 & \\
\hline
\end{tabular}

Table 1: Course Outline and Schedule

\section{Class composition and Academic Expectations:}

This class had a unique class composition, $20 \%$ students with 20 or more years of industrial experience ('Group A'), 40\% students with 10 or more years of industrial experience ('Group B'), 30\% graduate students with less than 2 years of experience ('Group C') and 10\% senior undergraduate students ('Group D') interested in pursuing career in automotive engineering. At the beginning of the course, instructor conducted a brief student survey with following questions.

a) Student comfort level in analytical/theoretical dynamics

b) Student comfort level in mathematical concepts like matrices, vectors transformation and calculus.

c) Student comfort level in modeling and drafting.

d) Student understanding of practical vehicle dynamics problems.

e) Student ability to correlate simulation results to actual experiments.

f) Student experience with actual vehicle handing/dynamic testing.

g) Students expectation (self learning objective).

The basic purpose of the survey was to tailor the course content to students' background, expectations and experience. The outcome of the survey questions (a-f) is presented in table 2.

\begin{tabular}{|l|l|l|l|l|}
\hline Question & $\begin{array}{l}\text { Group A } \\
\text { (>20 years of } \\
\text { experience) }\end{array}$ & $\begin{array}{l}\text { Group B } \\
(10-20 \text { years } \\
\text { of experience) }\end{array}$ & $\begin{array}{l}\text { Group C } \\
(<3 \text { years of } \\
\text { experience })\end{array}$ & $\begin{array}{l}\text { Group D } \\
\text { (<1 year of } \\
\text { industrial } \\
\text { experience })\end{array}$ \\
\hline $\begin{array}{l}\text { (a) comfort level in } \\
\text { analytical/theoretical } \\
\text { dynamics }\end{array}$ & Low & Medium & High & Medium \\
\hline $\begin{array}{l}\text { (b) comfort level in } \\
\text { math }\end{array}$ & Medium & Medium & Medium & Medium \\
\hline $\begin{array}{l}\text { (c) comfort level in } \\
\text { modeling and } \\
\text { drafting }\end{array}$ & Low & High & Medium & High \\
\hline (d) understanding of & High & High & Medium & Low \\
\hline
\end{tabular}




\begin{tabular}{|l|l|l|l|l|}
\hline practical problems & & & \\
\hline $\begin{array}{l}\text { (e)ability to } \\
\text { correlate simulation } \\
\text { results to actual } \\
\text { experiment }\end{array}$ & High & Medium & Low \\
\hline $\begin{array}{l}\text { (f) experience with } \\
\text { actual Hehicle } \\
\text { handing/dynamic } \\
\text { testing }\end{array}$ & & High & Low & Low \\
\hline
\end{tabular}

Table 2: Student Survey results

The students were asked to self evaluate on the scale of 1-10, where 1 is the lowest and 10 corresponds to the highest. The scale 'High' refers to score of 7 and above, 'Medium' refers to score of 4 to 7 and 'Low' refers to scores 3 and below.

Students from 'Group A' primarily, expected more understanding and correlation of software simulation and experimental testing. Students from 'Group B' wanted to focus on developing software as well as analytical skills. Students from 'Group C' expected more understanding of software and detailed modeling and analysis procedure. Students from 'Group D' were keen on learning software and simulation approaches.

\section{Instruction Methodology:}

It can be observed that the class population had a diverse background with lots of expectations from this course. The course involved some theoretical material and hands on projects using MSC Software. MSC software provided the teaching material for MSC-ADAMS. This teaching material is based on 'crawl-walk-run' approach. In this approach, students build and analyze models of progressively complex assemblies and systems. The instructor decided to adopt this approach with slight modifications (understand-crawl-walk-run). Initially, the theory material was presented that explained the theoretical concepts outlined in the text. Some simple tutorials were presented where students were guided thro' the modeling and analysis process ('crawl'). Later, project assignments (home-works) were given to the students so that students can work out problems on their own ('walk'). Finally, the students were assigned some real life project to test and hone their skills ('run'). At the beginning of the course, the students were presented with this teaching approach and suggested to select a project that can be developed in a building block approach. Interestingly, students in 'Group A' proposed to work on a project on a practical subassembly problem instead of a full vehicle. Students in 'Group B' proposed to model and analyze a vehicle dynamics problem for which experimental test data was available. Students in 'Group C' proposed to work on a vehicle subassembly-integration problem. Students in 'Group D' wanted to work on modeling and analysis of 'SAE-Mini Baja' subsystem and vehicle assembly problem. The students were asked to prepare project proposals that were reviewed by the instructor. Some of the project proposals were either too broad or too specific. Some proposals needed resources and background beyond the scope of the course. Another 
important factor emphasized by the instructor was that the projects should have a building block (subsystem-assembly-analysis-simulation-validation) approach that fitted 'understand-crawl-walk-run' teaching philosophy.

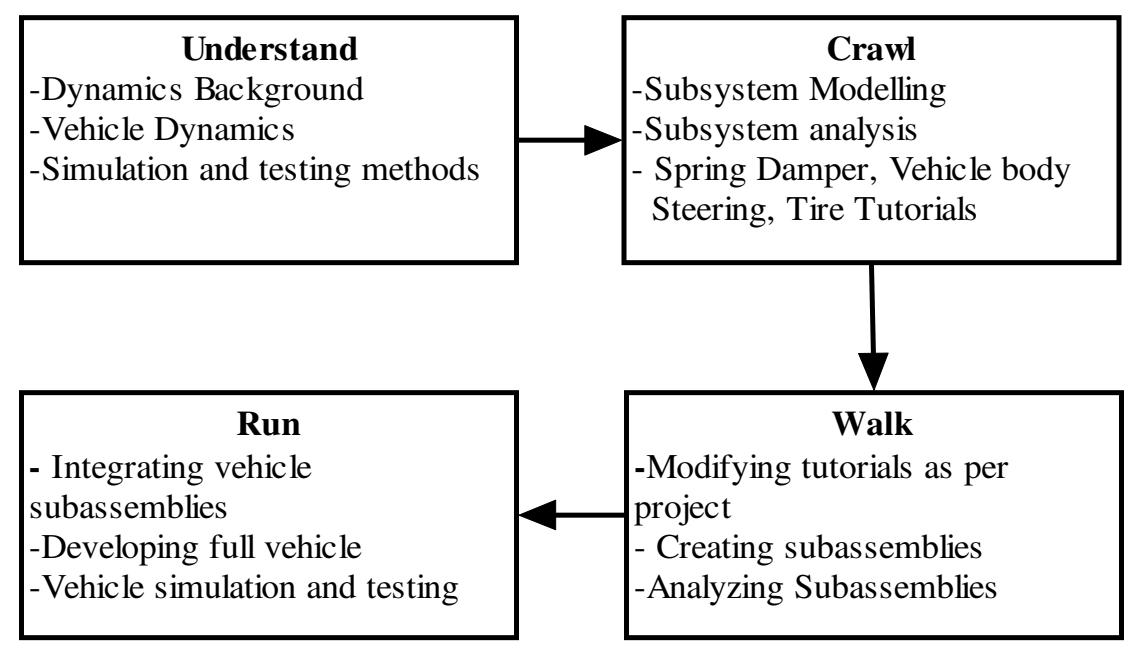

Figure 1: Teaching Methodology

Some of the sample projects students worked on were

a) Trailer Analysis ('Group A'): In this project, student proposed to study dynamic performance of larger trailers with a load compensating linkage between the front and rear spring systems and compare to industry standard, conventional approach simple shackle interconnection.

b) Modeling and dynamic simulation of SUV-trailer combination ('Group B'): In this project, student proposed to analyze a SUV-Trailer combination and study pulse steer, yaw mode oscillatory stability and constant steer under-steer testing.

c) Dynamic analysis and testing of surge brake ('Group C'): In this project, student proposed to model, analyze and simulate surge brake assembly. The results would be compared to experimental results.

d) Dynamic analysis of torsion bar system ('Group C'): In this project, student proposed to model, simulate and analyze a torsion bar system for trailers.

e) Steering-Suspension system analysis ('Group D'): In this project, student proposed to model analyze sample steering-suspension geometry and create a template. This assembly would be similar to SAE-Mini Baja car suspension-steering system.

As students started working on the project, they encountered several problems. A MSC hands-on workshop was organized by the Engineering Technology department and Advanced Technology Innovation Center at ASU-Polytechnic Campus [6]. The university program manager of MSC software enthusiastically expressed her support this event and helped in organizing.

The objective of this workshop was to introduce faculty, students and practicing engineers to MSC software products, discuss MSC university program, and explore opportunities to increase collaboration between MSC. Software Corporation, ASU and 
local business entities, and present two hands on sessions (described below) to familiarize participants with Virtual Product Development (VPD) technology.

\section{Session I: MSC.ADAMS-Mechanical System Simulation}

In this session, the speaker discussed MSC ADAMS. Often called a multi-body dynamics program, ADAMS is MSC's tool for studying systems with large motions, with both rigid and flexible bodies without any assumptions about linearity. ADAMS automatically includes both geometric and inertial nonlinear effects. Typical applications from orbital dynamics and full-vehicle handling down to disc drive head response and nano-fabricator controls were presented.

\section{Session-II: MSC. Nastran-Finite Element Analysis}

In this session, applications of MSC's analytical simulation software to support effective design and assessment of product designs were presented. The speaker demonstrated the Finite Element modeling process by presenting a linear static problem and a more complex transient dynamic impact problem.

In the question and answer session of the seminar, experts from MSC software presented relevant material on MSC-ADAMS pertaining to MET 591 class projects and answered students' questions. This seminar was well received by students, faculty and local industries. The students had a chance to meet engineers from MSC software, representative from local industries that use MSC Software products, understand the software capabilities and the direction in which virtual product development industry is headed. It was a great networking opportunity for students, faculty and engineers from local industries.
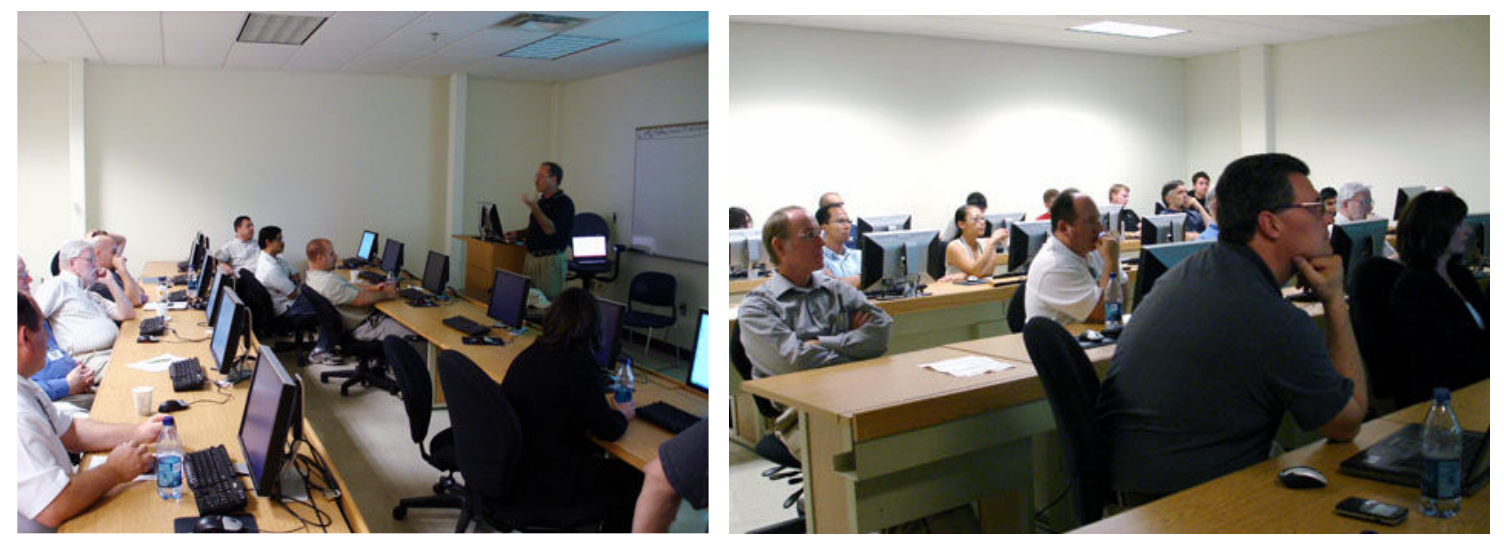

Figure 2: MSC Software Hands on workshop

Based on the inputs from instructor, engineers from MSC software and class discussions, students successfully worked on the projects and presented their work during the last week of semester. 


\section{Student Course Evaluation and Teaching Effectiveness:}

At the end of the course, course evaluations were conducted. At ASU-Poly, a course is evaluated on the basis of 17 criterions. The students evaluate course (exclusive of instructor based on following 7 questions).

EVALUATION OF THE COURSE (exclusive of the instructor)

1. Textbook/supplementary material in support of the course

2. Value of assigned homework in support of the course topics.

3. Value of laboratory assignments/projects in support of the course topics.

4. Reasonableness of exams and quizzes in covering course material.

5. Weight given to labs or projects, relative to exams and quizzes.

6. Weight given to homework assignments, relative to exams and quizzes.

7. Definition and application of criteria for grading.

The students also evaluate the instructor on following 10 criterions.

\section{EVALUATION OF THE INSTRUCTOR}

8. The instructor was well prepared.

9. The instructor communicated ideas clearly.

10. The instructor or assistants were available for outside assistance.

11. The instructor exhibited enthusiasm for the interest in the subject.

12. The instructor's approach stimulated student thinking.

13. The instructor related course material to its applications.

14. The instructor's methods of presentation supported student learning.

15. The instructor's grading was fair, impartial and adequate.

16. The instructor returned graded materials within a reasonable period.

17. Overall quality of the course and instruction

Students grade the course and instructor on scale of A to E. A sample evaluation sheet is shown in figure 4 . This survey is compiled and assigned a numeric score between 2 and 5 (where 5-Very Good, 4-Good, 3-Fair, 2-Poor). Teaching is considered very important in Engineering Technology Department at ASU and departmental teaching evaluation averages are typically very high. The instructors do not have access to the evaluation data before the grades are posted. The Students also provide feed back on

26. What did you like the most about the course?

27. What did you like least about the course?

These evaluations are very useful to access the effectiveness of the course and instructor and provide valuable information so that the course can be improved. In figure 4, the course evaluations for MET 591: Advanced Vehicle Dynamics are presented and compared with the departmental course evaluation averages. 


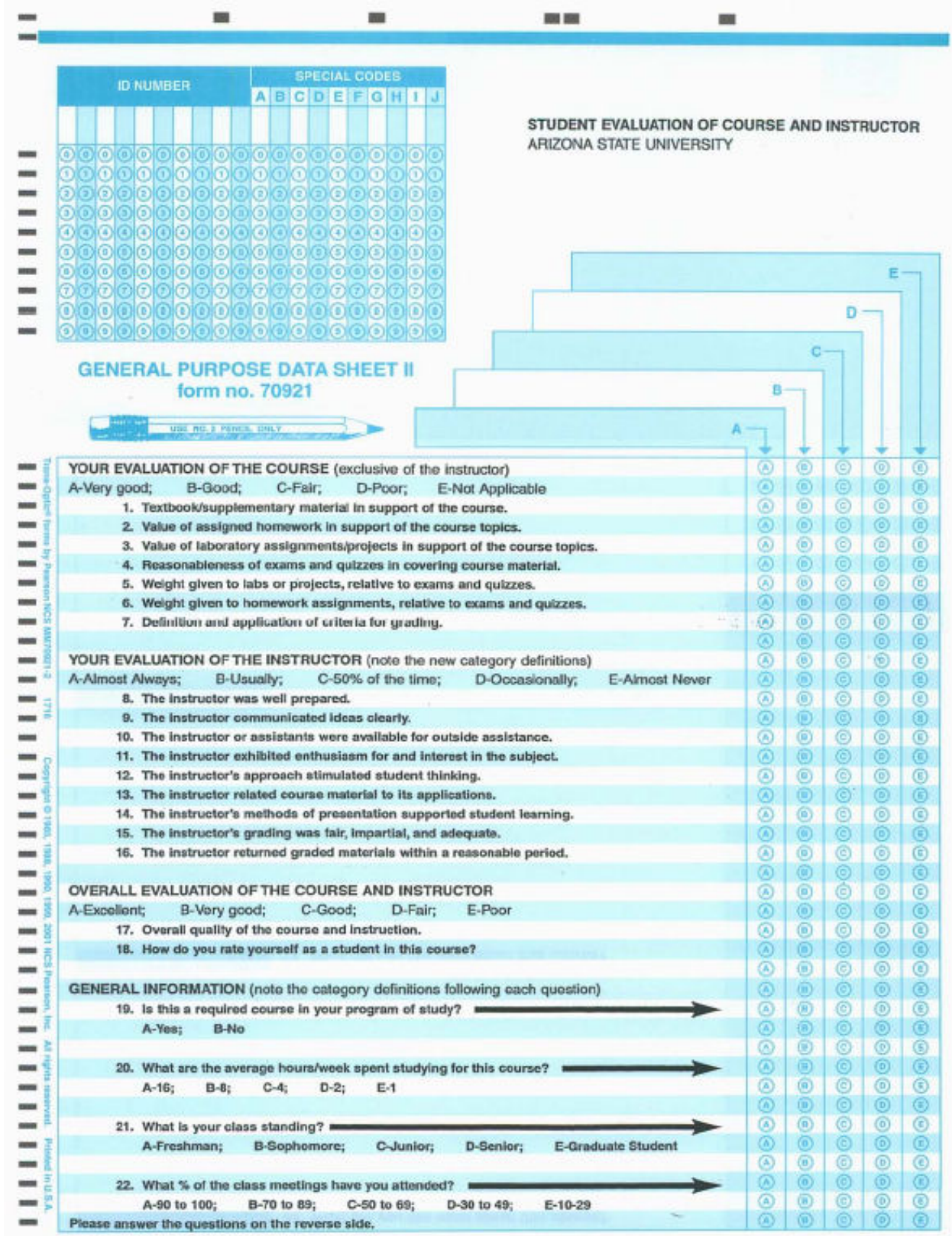

Figure 4: Course Evaluation Form used at ASU-Poly

The student liked (Answers to Question 26) 'The project and overall objective of the course-industry and school collaboration', 'ADAMS software and exercises'. Some students mentioned (Answers to Question 27) that 'Introductory class to ADAMS software would be helpful' and 'Not enough time covering a lot of topics' It can be observed from figure 5 that course evaluation for MET 591 exceeded the departmental average. 


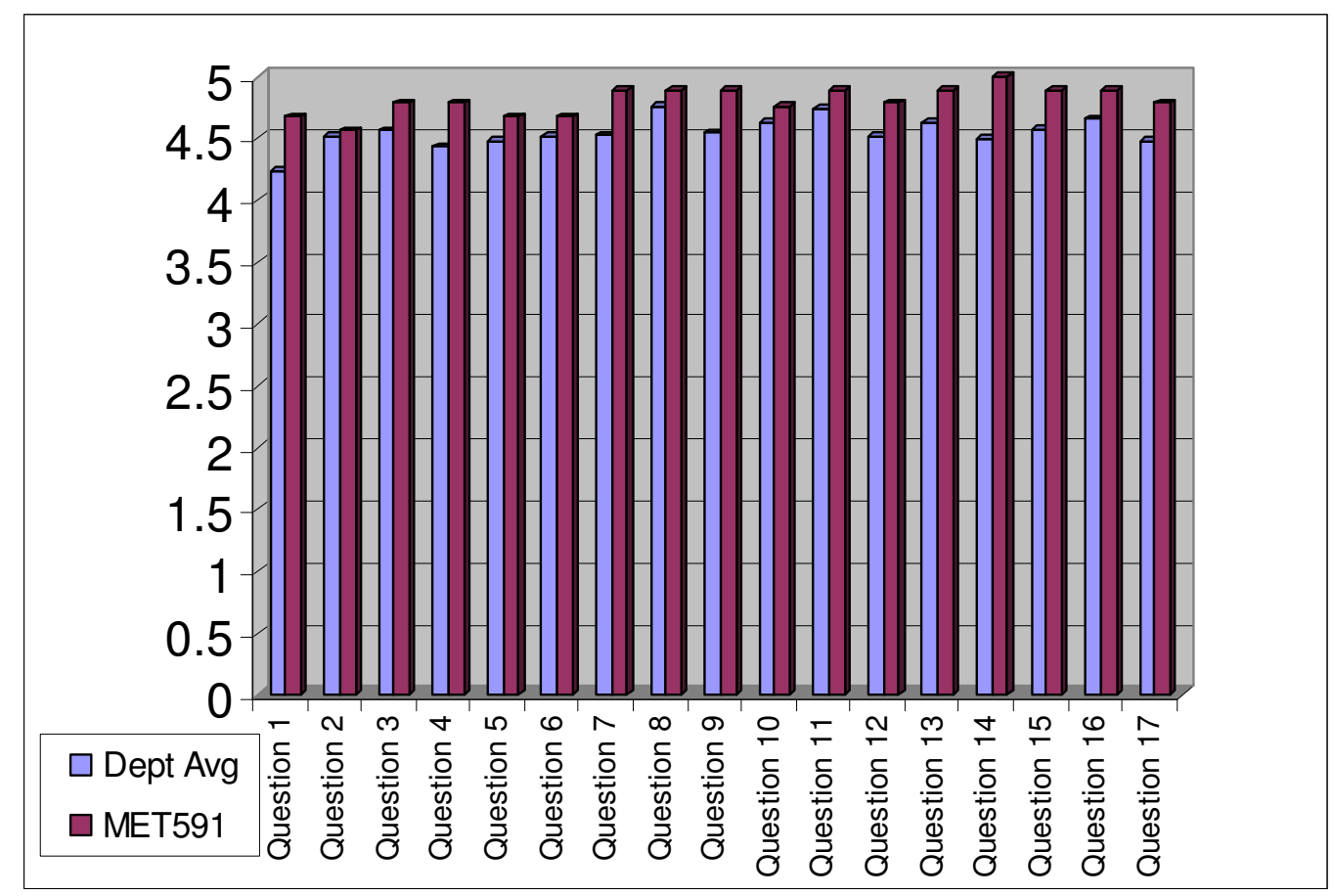

Figure 5: Teaching Evaluations for MET 591: Advanced Vehicle Dynamics

\section{Conclusion:}

This 'Advanced Vehicle Dynamics' course presented a case where Arizona State University, local industries and MSC software came together to offer students an excellent educational experience. The instructor adopted understand-crawl-walk-run type of teaching philosophy mixing theory and practice. Due to the diverse class composition and varied student expectation, the instructor used a project based leaning approach where students could concentrate and achieve their individual learning goals. The routine class discussions helped students to solve their problems. A hands on workshop was organized for the problems and questions that needed an 'expert help'. Based on informal discussion with students and formal class evaluations it can be concluded that students enjoyed the course and course objectives were met satisfactorily.

\section{Acknowledgement:}

The author would like to thank Mr. Paul Grabill of U-Haul Technical Center, Mr. Dan Abir, Mr. Lindley Bark and Dr. Andrew Elliot of MSC Software. Special words of thanks go to Ms. Casey Radigan, University Program Manager at MSC software for her help and support. The author is also thankful to Dr. Mike Blundell for sharing his course material. The author is also thankful to Dr. Anshuman Razdan and Ms. Jane Laux for their help and support in organizing MSC software workshop through ATIC. 


\section{Bibliography:}

1. www.mscsoftware.com

2. www.uhaul.com

3. http://www.mscsoftware.com/university/

4. M. Blundell and D. Harty, 'The Multibody Systems Approach to Vehicle Dynamics' Elsevier Publishing 2007.

5. http://wwwm.coventry.ac.uk

6. http://atic.asu.edu/

$\mathbb{0}$
$\mathbb{0}$
$\mathbb{D}$
$\vec{\perp}$
$\vec{D}$
$\vec{D}$
$\stackrel{\Xi}{\Xi}$ 